\title{
Hardware in the loop simulative setup for testing the combined heat power generating wind turbine
}

\author{
Ihor Shchur', Vsevolod Shchur ${ }^{2}$, Ihor Bilyakovskyy ${ }^{3}$, Mykhailo Khai ${ }^{4}$ \\ ${ }^{1,3,4}$ Department of Electromechatronics and Computerized Electromechanical Systems, Institute of Power Engineering \\ and Control Systems, Lviv Polytechnic National University, Bandera, Ukraine \\ ${ }^{2}$ Mita-Teknik Ltd., Lviv, Ukraine
}

\section{Article Info}

Article history:

Received Jun 11, 2020

Revised Jan 1, 2021

Accepted Jan 22, 2021

\section{Keywords:}

Electromagnetic heat generator Hardware in the loop simulator Permanent magnet synchronous generator

Vertical axis wind turbine

Wind energy conversion system Combined heat-power generation

\begin{abstract}
This paper describes the design and implementation of hardware in the loop (HIL) system based on induction motor wind turbine emulator for the study of the operation of a combined heat-power (CHP) generating wind energy conversion system (WECS). The energy generation part of the WECS consists of two specially designed generators that are placed on a common vertical axis, which is connected to the induction motor through a gearbox. The first generator is an electric two-armature axial PMSG and the second one is a thermal electromagnetic retarder. The software part of the HIL setup simulates the interaction of the wind flow with a vertical axis wind turbine (VAWT) and is implemented in a programmable logic controller based on the model developed in the MATLAB/Simulink. The results of experimental studies of the CHP WECS with the created HIL simulative setup at both constant and turbulent wind speeds have shown good agreement with the corresponding results of computer simulation. The created HIL simulative setup will be used for the development of an energy management system for CHP WECS.
\end{abstract}

This is an open access article under the CC BY-SA license.

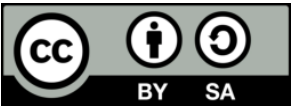

\section{Corresponding Author:}

Ihor Shchur

Institute of Power Engineering and Control Systems

Lviv Polytechnic National University

Bandera str. 12, Lviv, 79013, Ukraine

Email: ihor.z.shchur@lpnu.ua

\section{INTRODUCTION}

Renewable energy development rates are steadily increasing in many countries. Wind power generated by high-power wind turbines (WT) occupies a prominent place in this process [1]. At the same time, low-power (up to $10 \mathrm{~kW}$ ) wind energy conversion systems (WECS) which, as a rule, stand alone are now becoming more widespread [2], [3]. Some consumers use them for power supply in the absence of centralized power grids or in the presence of the latter for additional power supply in order to reduce electricity consumption from a grid, improve energy efficiency and ensure uninterrupted power supply.

Low-capacity WTs are installed directly near consumers where wind is mainly characterized by low average speeds, frequent gusts, change of direction, and high turbulence. The location and specific characteristics of the wind account for the significant difference between low-power WT's structures and traditional high-power ones, in particular at the use of WTs with vertical axes of rotation (VAWT) [4]. These VAWTs work effectively with gusty winds, constantly perceive winds of different directions, and start at low wind speeds thanks to the direct (gearless) drive of a low-speed permanent magnet synchronous generator (PMSG) [5]. 
In stand-alone WECS, due to the stochastic nature of electricity generation and consumption, electrochemical batteries (B) are most commonly used to ensure the power supply and better use of generated electricity [6]. However, their high cost and relatively low lifetime significantly increase the total cost of a WECS-based autonomous power supply system. To save money, we can reduce the capacity of the installed Bs; as a result, the amount of generated electricity that cannot be directly consumed or accumulated will increase. This dump energy is either lost by reducing the VAWT power generated or is utilized by loading the generator on thermoelectric heaters. The latter are placed in a hot-water boiler used to heat buildings and for hot water supply [7]. WECS that produces electrical and thermal energy can be called a combined heatpower (CHP) generating one.

In the known CHP WECSs, heat is obtained from electricity already generated. The heat flow capacity thus limits the permissible power of the electric generator. A new alternative solution is to use in WECSs, in addition to the traditional PMSG, a heat generator that will transform the mechanical energy of the WT directly into thermal energy, bypassing the intermediate electrical link [8], [9]. The heat generator is an electromagnetic device-retarder, in which the eddy currents generated in the rotor array by the magnetic flux produced by an excitation winding during rotor rotation, ensure its heating. The generated heat is transferred to the water that is periodically pumped into a heat collector. The special heat generator is much simpler and has a significantly higher specific power compared to the electric one, and hence its low cost [9]. Such a solution has several advantages-enhancing the functionality of CHP WECS, increasing its energy efficiency, and reducing the total cost due to the possibility of not using Bs [8]. The efficient operation of CHP WECS requires the development of a dedicated energy management system that will perform the functions of optimal control of power extracting from the wind, electricity and heat generation and consumption, as well as monitoring of energy processes.

In order to conduct experimental research in the above directions, it is necessary to create a special installation. In the latter, it is advisable to replace the most difficult aerodynamic part of WT by the corresponding simulator. Much work has been done to develop such tools, called emulators or Hardware-Inthe-Loop (HIL) simulators for the study of WECSs and the development of control systems [10]-[14]. They are distinguished by the degree of emulation, hardware and software solutions, and the purpose of research that will be conducted using these installations.

In almost all simulators or emulators, wind flow and its interaction with WT are mathematically simulated. Neammanee et al. [10] have modeled the wind flow using the Van der Hoven spectrum, and the torque ripple caused by tower effect was taken into account. WT work has been simulated by induction motor (IM) whose torque has been controlled by an inverter. A feature of the Wind Turbine Emulator (WTE) presented in [11] is the simple modeling of the aerodynamic characteristics of the WT using a DC motor with separate excitation and a series power resistor. Such an implementation does not require a controller with complex control algorithms, but the characteristics obtained in the open system are very close to the real characteristics of the WT. In [12], the DC motor controlled by a half-bridge DC-DC converter in double-loop control system physically provides the angular velocity of WT given by the controller. Garg and Dahiya [13] developed the WTE which is based on a DC motor driving a self-excited induction generator that is practically not used in either large or small WECSs. In [14], the laboratory-scale WTE simulates both the operation of the WT with a wound rotor induction generator and the inverter connected to the network. Emphasis is placed on providing a real-life wind speed profile as well as modeling the starting of WT and its control by a pitching mechanism.

In recent years [15]-[19], the term "emulator" is often replaced by HIL setup or HIL platform. These are usually closed-loop systems that cover both hardware and software parts of the system, which are connected through a power amplifier with interface algorithm. In the proposed solution, a wind velocity profile, WT characteristics and control systems are simulated by the HIL system. By using such HIL system, it is possible to reproduce the actual operating conditions of WT's working with different types of generators in the laboratory environment. In addition, this approach allows to conduct other investigations directed at the development of control strategies of WECS, such as pitch control and MPPT [16], [18] and testing of wind turbine nacelles for electrical certification [19].

This article is about creating a new CHP WECS stand with HIL simulative setup of VAWT's work. It consists of the drive IM that emulates the VAWT torque under the action of the wind flow of given profile and two specially designed generators-an electric two-armature PMSG of axial type and a thermal electromagnetic retarder. Two generators are placed on a common vertical axis. Software part of the HIL simulative setup, which simulates the interaction of wind flow with VAWT and generates the corresponding reference for the frequency converter that controls the IM torque, is implemented in the PLC, based on the model developed in the MATLAB/Simulink software. This model ensures the equivalence of the real VAWT's work with specific parameters and the HIL simulative setup. The application of the created stand in experimental research will allow to model various wind conditions with the possibility of their identical 
repetition and to develop effective flexible algorithms of management of power flows, providing the consumer with electric and thermal energies.

To make the contribution of this paper clearer, the article will be structured as follows: the development of the hardware part of the stand is briefly highlighted in Section 2. Then, the development of the software part of the HIL simulative setup is introduced in detail in Section 3. The obtained simulation results based on the MATLAB/Simulink software and experimental results obtained on the stand of CHP WECS for the modes of power and heat generation are compared in Section 4. Finally, the conclusion is given in Section 5.

\section{HARDWARE PART OF THE STAND}

\subsection{Electrical and heat generators}

The PMSG that was designed and manufactured for the study of the CHP WECS stand has an axial construction. It consists of two identical armatures between which there is a steel disk rotor with permanent magnets placed on both sides of the disk as shown in Figure 1. To eliminate a tooth torque, the generator armatures have a smooth (toothless) construction. The winding coils are glued to the surface of the laminated disk yoke. The same name phase windings of both armatures are set forth in phase and connected in series. The parameters of the PMSG are given in Table 1.

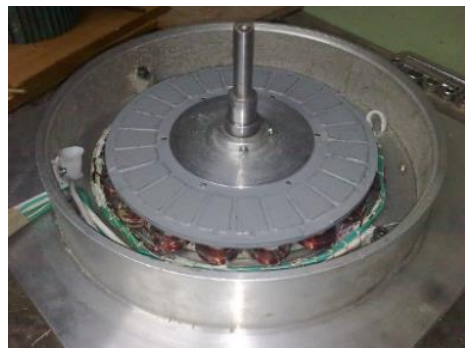

(a)

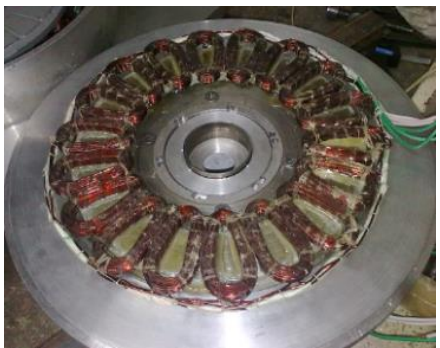

(b)

Figure 1. Two-armature axial PMSG manufactured for the stand: (a) first armature and disk rotor with permanent magnets, (b) second armature

Table 1. Parameters of the PMSG

\begin{tabular}{cc}
\hline Parameter & Value \\
\hline Rated power [W] & 300 \\
Rated phase voltage [V] & 18 \\
Rated speed [rpm] & 250 \\
Rated torque [N·m] & 11.5 \\
Number of pairs of poles & 12 \\
Phase winding resistance $[\Omega]$ & 0.528 \\
Winding inductance $[\mathrm{H}]$ & 0.0011 \\
Flux linkage by PM [Wb] & 0.0594 \\
\hline
\end{tabular}

In our proposed rotating electromagnetic transformer of mechanical energy into heat (ETMEH) as shown in Figure 2 [8], the fixed inductor 1 has the circular placed steel teeth 2, on which the coils 3 are arranged. To increase the cross-sectional area of the magnetic circuit in the air gap, the teeth are equipped with the steel tips 4 . The steel disk 5 is fixed to the vertical rotation shaft 6 of the VAWT and is placed at minimum distance from the tips. The thin layer 7 of a non-ferromagnetic material with high electrical conductivity (copper) is applied on the surface of the disk 5. If the coils are connected in series, their ends are turned one at a time and direct current flows through the coils, a constant magnetic flux of alternating polarity will be closed through the disk body. As the disk rotates, this flow at each point in the disk body will already be variable, which will be accompanied by the generation of EMF in the disk and, accordingly, eddy currents. They will be particularly significant in the non-ferromagnetic layer on the disk. Joule heat from eddy currents is a positive effect of the ETMEH. To use it, the disk must have good thermal contact with the coolant liquid 8, which will transfer heat to the storage water heater. The ETMEH is placed in the housing 9, which is well insulated thermally. 


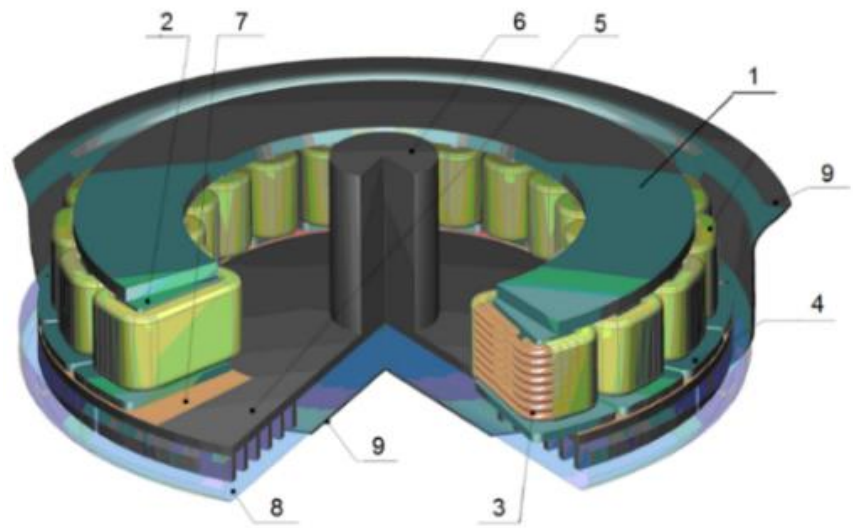

Figure 2. The sketch of the ETMEH

A magnitude of the generated heat flow will depend on the geometry of the EPMEH design, the magnetizing force of the inductor, which can be controlled by changing the excitation current, the rotation speed of the disk, and its structure. The design and optimization of the ETMEH parameters were carried out using the ANSYS software for field modeling by the finite elements method (in this case magnetic and thermal field) [20].

According to the results of the calculations, the experimental prototype of ETMEH with the inductor consisting of 20 teeth with the coils was designed and manufactured. It is rated for a thermal output power of $1000 \mathrm{~W}$ at a rotational speed of $250 \mathrm{prm}$, an excitation current of $2.0 \mathrm{~A}$, and an excitation winding voltage of $12 \mathrm{~V}$. At the same time, $25 \mathrm{~W}$ of electrical power is used for the excitation, that is, the ETMEH rated efficiency is not lower than 0.95 . The outer diameter of the inductor yoke is $340 \mathrm{~mm}$, its coil height is 42 $\mathrm{mm}$. The basic design elements of the experimental prototype are shown in Figure 3.

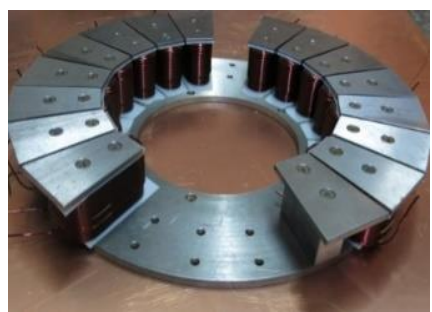

(a)

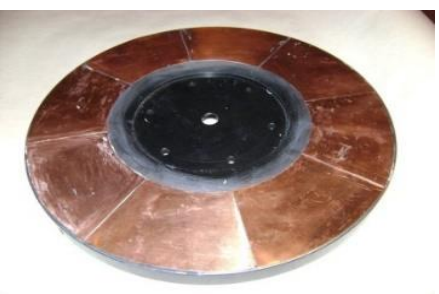

(b)

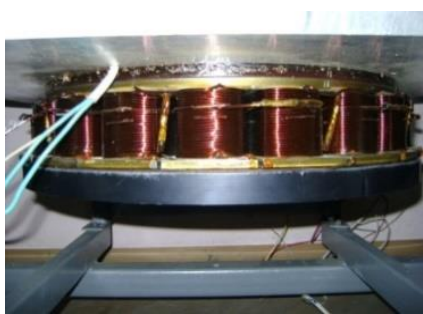

(c)

Figure 3. Basic elements of the design of the ETMEH experimental prototype: (a) inductor with 20 poles, (b) rotor with copper surface layer, (c) prototype assembled

\subsection{Hardware part of the WTE}

To implement the WTE hardware, the squirrel cage IM of a rated power of $1.5 \mathrm{~kW}$ and a rated speed of $2860 \mathrm{rpm}$ was used. To make it conform to the PMSG and ETMEH speed, a worm gearbox with the gear ratio of $\mathrm{i}=12$ was applied. The control function of the IM is assigned to the frequency converter Lense 8200 Vector with a power of $1.5 \mathrm{~kW}$, powered from a single-phase network of $220 \mathrm{~V}$. The choice of this type of frequency converter is due to it having the option of vector control of the electromagnetic torque.

The functional schema of the stand for the CHP WECS study in Figure 4 shows that the WTE includes the IM, the frequency converter FC and the worm gearbox G that connects the IM to the electrical PMSG and to the heat generator ETMEH. All control functions including WTE control are implemented by the PLC. For this purpose, it contains on-line working subroutines for shaping the turbulent wind speed vw, corresponding to the value of the mechanical WT torque TWT, as well as the corresponding reference of the MI torque $\mathrm{T}^{*}$. To calculate the latter two, the angular velocity of WT is required. An induction pulse sensor IPS measures the IM speed by operation during each approach of the blades of a cooling fan. The pulses from IPS go to a pulse input of the PLC which by its own program performs digital filtering and calculates the angular velocity of PMSG based on the gear ratio $i$. 
The stand also includes tools that provide various possibilities for generating and storing electrical and thermal energy, as well as managing the flows of these energies. The electricity generated by the PMSG can be stored in an electrochemical battery B that is connected to the PMSG armature windings via a diode bridge VD and a DC-DC1 transistor boost converter. The DC-DC1 controls the power transmitted to the B. In addition, power can be extracted from the PMSG and converted to heat when the thermoelectric heaters TEH are connected to the armature winding and placed in a storage water heater. The heat generation capacity can be regulated, for example, by periodically connecting the TEH to the triac switches TVR [21]. The regulation of the thermal flow generated by the ETMEH is accomplished by varying the current in its excitation winding by means of the DC-DC2 converter. Figure 5 shows pictures of the created stand.

A number of studies were conducted to determine the basic parameters of the created stand.

The torque of dry friction on the IM shaft Tc.s(IM) is determined by means of measuring by a dynamometer the force $\mathrm{F}$ applied to a thread wound on the cylindrical surface of the coupling with a radius $\mathrm{rm}=0.05 \mathrm{~m}$. As a result, Tc.s $(\mathrm{IM})=\mathrm{F} \mathrm{rm}=1.03 \mathrm{~N} \cdot \mathrm{m}$.

The mechanical characteristics of the stand during its idle stroke were obtained thanks to the possibility of measuring the rotational speed of the IM and the electromagnetic torque given to it by the frequency converter. As a result, the value of the coefficient of viscous friction on the IM shaft of bs $(\mathrm{IM})=0.0013 \mathrm{Nm} \cdot \mathrm{s}$ was determined.

The moment of inertia of the stand relative to the IM shaft Js(IM) was determined by the Atwood machine method-motion under the action of a load. To exclude from the calculation the friction force, it is necessary to carry out two experiments with two different loads [22]. Each of them was hung in turn on a cord thrown over the block and wound on the same surface of the coupling with radius rm. Under the influence of its weight, the load was dropped evenly from the height $h=2.44 \mathrm{~m}$, while the time of its movement was measured. After a series of experiments and averaging the results, we obtained the following: for a load of $\mathrm{m} 1=4 \mathrm{~kg}$, the lowering time was $\mathrm{t} 1=1.385 \mathrm{~s}$, for a load of $\mathrm{m} 2=6 \mathrm{~kg}, \mathrm{t} 2=0.987 \mathrm{~s}$. The determined values of accelerations were $a_{1}=2 h / t_{1}^{2}=2.544 \mathrm{~m} / \mathrm{s} 2$ and $a_{2}=2 h / t_{2}^{2}=5.01 \mathrm{~m} / \mathrm{s} 2$ respectively. The moment of inertia of the stand was equal to $0.0247 \mathrm{~kg} \cdot \mathrm{m} 2$ as a result of the calculation by the expression [22]

$$
J_{S(\mathrm{IM})}=r_{m}^{2} \frac{m_{2}\left(\frac{g}{2 h}-\frac{1}{t_{1}^{2}}\right)-m_{1}\left(\frac{g}{2 h}-\frac{1}{t_{2}^{2}}\right)}{t_{2}^{-2}-t_{1}^{-2}}
$$

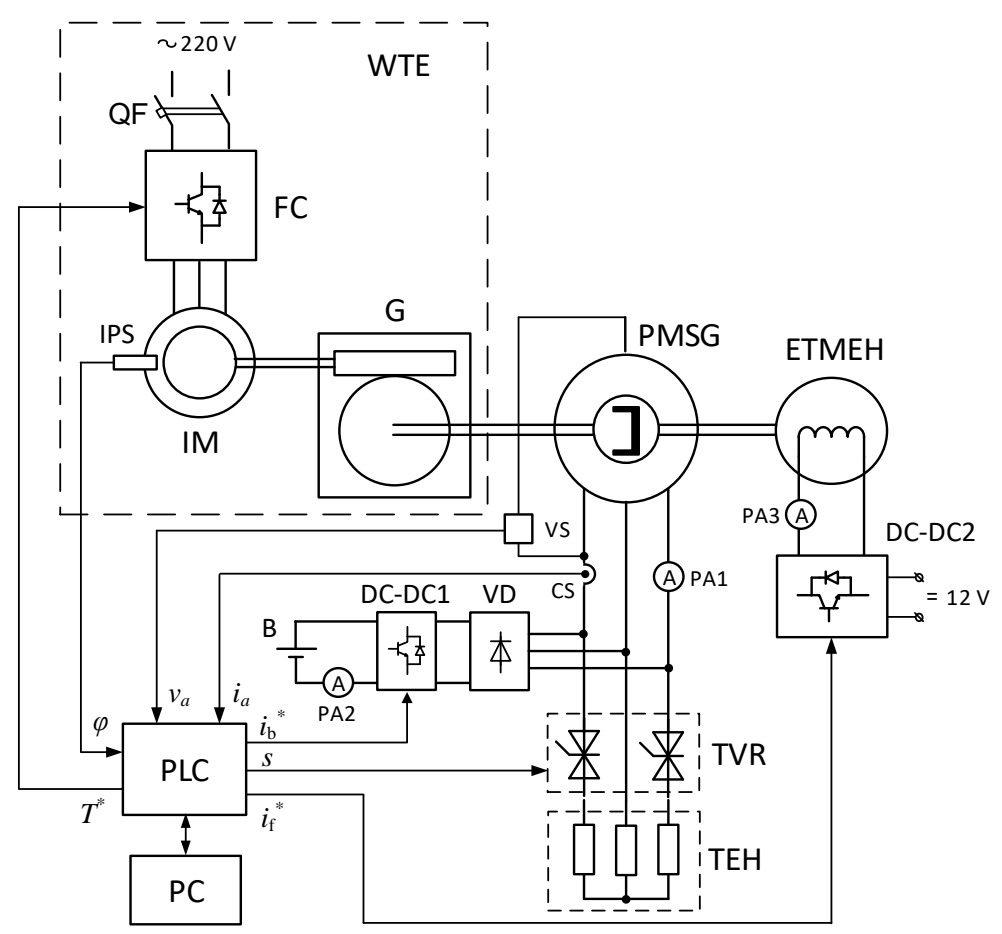

Figure 4. Functional schema of the stand for testing of CHP WECS 


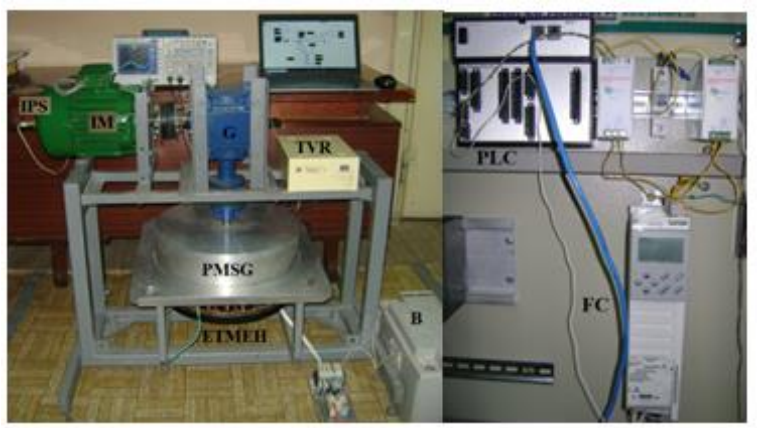

Figure 5. Stand for the testing of CHP WECS

\subsection{PLC for HIL simulative setup}

The PLC WP130 MK II produced by Mita-Teknik Ltd as shown in Figure 5 [22], [23], controls the experimental stand. This PLC is specially designed to control WTs with a rated power of up to $1 \mathrm{MW}$. It includes a set of different I/O channels for both digital and analog signals. This makes it possible to use the controller as a stand-alone device (without additional modules) to control less complex systems.

With the Software Development Kit created by Mita-Teknik for the MATLAB/Simulink, it was possible to compile the Simulink model source code for the WP130 MK II controller platform. To do this, one must pre-set blocks of input and output variables in the model that will link MATLAB/Simulink algorithms to the controller program variables and the inputs/outputs of the interface channels. The PEPTOOL programming environment then allows the compiled code to be built into the application for the WP130 MK II controller. Thus, by creating a virtual object of the control system in MATLAB/Simulink, we can apply a developed and debugged algorithm for a real object control system based on the Mita-Teknik controller.

To obtain the results of the controller WP130 MK II, as well as to debug the program, the controller operating system provides the recording of values of any variables from the database to a file in real time. The recorded variable data can be represented as waveforms or tabular values.

\section{SOFTWARE PART OF THE HIL SIMULATIVE SETUP}

To form the IM torque control law that adequately simulates the VAWT operation on a given wind profile, we consider two electromechanical systems as shown in Figure 6: (a) the VAWT directly drives the PMSG; (b) the WTE with the controlled IM drives the PMSG through the gearbox with the gear ratio i. The torque balance of the generator's shaft, under the condition of the absolute rigidity of mechanical transmission, for both of these systems is described by the following (2):

- for WECS with VAWT

$$
T_{\mathrm{wT}}=T_{\mathrm{em}}+T_{\mathrm{c}}+b \omega+J_{\Sigma} \frac{\mathrm{d} \omega}{\mathrm{d} t}
$$

where $T_{\mathrm{em}}$ is the electromagnetic torque created by the PMSG, $T_{\mathrm{c}}$ is the torque of dry friction in the VAWT's shaft, and $J_{\Sigma}$ is the total moment of inertia of the VAWT with the rotors of the generator; - for the stand with WTE neglecting the backlash in mechanical transmission

$$
i T_{\mathrm{IM}}=T_{\mathrm{em}}+T_{\mathrm{c} . \mathrm{(G})}+b_{\mathrm{s}(\mathrm{G})} \omega+J_{\mathrm{s}(\mathrm{G})} \frac{\mathrm{d} \omega}{\mathrm{d} t}
$$

where the subscript $s(G)$ means belonging to the stand relative to the generator shaft. 


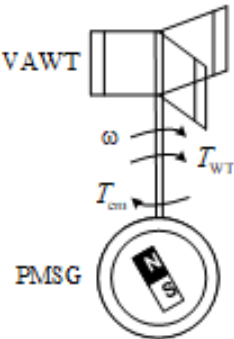

(a)

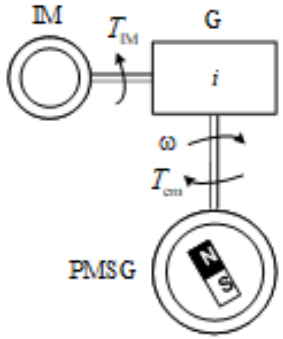

(b)

Figure 6. Schemes of electromechanical systems: (a) WECS, (b) stand with WTE

Considering that

$$
T_{\mathrm{c} . \mathrm{s}(\mathrm{G})}=i T_{\mathrm{c} . \mathrm{(IM})}, J_{\mathrm{s}(\mathrm{G})}=i^{2} J_{\mathrm{s}(\mathrm{IM})}, b_{\mathrm{s}(\mathrm{G})}=i^{2} b_{\mathrm{s}(\mathrm{IM})}
$$

and removing from (2) and (3) $T_{\mathrm{em}}$, we obtain the torque control law on the IM's shaft which will provide identical work of the WECS and the stand with WTE simulating the VAWT's operation:

$$
T_{\mathrm{IM}}=\frac{1}{i}\left[T_{\mathrm{WT}}-\left(T_{\mathrm{c}}-i T_{\mathrm{c} .(\mathrm{IM})}\right)-\left(b-i^{2} b_{\mathrm{s}(\mathrm{IM})}\right) \omega-\left(J_{\Sigma}-i^{2} J_{\mathrm{s}(\mathrm{IM})}\right) \frac{\mathrm{d} \omega}{\mathrm{d} t}\right]
$$

For verification the accuracy of the obtained in (5), computer simulations of the electromechanical systems of the WECS and the stand with WTE shown in Figure 6 were performed in MATLAB/Simulink. Also, the simulation studies showed that, for the physical modeling of the operation of the electro-thermal WECS with two-armature PMSG and the ETMEH with the above-mentioned parameters, it is fit the VAWT with rated electric power of $P_{\mathrm{el}}=0.5 \mathrm{~kW}$, which is reached at a nominal wind speed of $V_{\mathrm{w} . \mathrm{n}}=10 \mathrm{~m} / \mathrm{s}$. We chose a three-blade H-rotor VAWT with the radius $r$. Its aerodynamic characteristic $C_{\mathrm{P}}(\lambda)$-dependence of the power coefficient on the wind tip speed ratio (TSR) $\lambda=\omega r / V_{\mathrm{w}}$ was chosen as the following for this research:

$$
C_{\mathrm{P}}(\lambda)=1.14\left(\frac{9.47}{\lambda}-1\right) e^{\frac{-6.0}{\lambda}}
$$

The dependence (6) provides the maximum value of $C_{\mathrm{P} \max }=0.3514$ at the optimum value of $\lambda_{\text {opt }}=3.675$. The VAWT's parameters for the experimental WECS were calculated by the expression as shown in Table 2.

$$
P_{\mathrm{WT} . \mathrm{n}}=\frac{P_{\mathrm{el} . \mathrm{n}}}{\eta_{\Sigma}} \quad A=\frac{P_{\mathrm{WT} . \mathrm{n}}}{0.5 \rho_{\mathrm{a}} C_{\mathrm{P} \max } V_{\mathrm{w} . \mathrm{n}}^{3}}, r=\sqrt{\frac{A}{2}}, \omega_{\mathrm{n}}=\frac{\lambda_{\mathrm{opt}} V_{\mathrm{w} . \mathrm{n}}}{r} \quad T_{\mathrm{WT} . \mathrm{n}}=\frac{P_{\mathrm{WT} . \mathrm{n}}}{\omega_{\mathrm{n}}}
$$

Where $\eta_{\Sigma}=0,85$ is the total efficiency of the PMSG and mechanical transmission, $A$ is the swept area of the VAWT.

These parameters were incorporated into the computer model to calculate the current $T_{\mathrm{WT}}$ values at different wind speeds and different angular velocities of the VAWT.

Table 2. Parameters of the VAWT for the stand of CHP WECS

\begin{tabular}{ccccccc}
\hline WECS & \multicolumn{7}{c}{ VAWT } \\
\hline$P_{\text {el.n }}$ & $P_{\mathrm{WT} . \mathrm{n}}$ & $A$ & $r$ & $\omega_{\mathrm{n}}$ & $T_{\mathrm{WT} . \mathrm{n}}$ & $J_{\Sigma}$ \\
{$[\mathrm{kW}]$} & {$[\mathrm{kW}]$} & {$\left[\mathrm{m}^{2}\right]$} & {$[\mathrm{m}]$} & {$[\mathrm{rad} / \mathrm{s}]$} & {$[\mathrm{N} \cdot \mathrm{m}]$} & {$\left[\mathrm{kg} \cdot \mathrm{m}^{2}\right]$} \\
0.5 & 0.588 & 2.724 & 1.41 & 26.0 & 22.6 & 14.0 \\
\hline
\end{tabular}


Figure 7 shows a common computer model of the general control system implemented in MATLAB/Simulink with the connected input/output ports of the PLC. This control system implements the wind speed simulator (Wind Simulation), the VAWT model (Wind Turbine Subsystem), as well as the subsystems of optimal control of the PMSG loading by the TEH (Puls Control Subsystem) and optimal control of the ETMEH excitation (If ETMEH). The model has some I/O ports indicated by different colors: one discrete input port (blue) DI_RotorFreq-the pulse rate of the IM speed, two analog output ports (yellow)AO_TorqueSP_V is the electromagnetic torque reference of the IM and AO_If_EPMET_V is the excitation voltage of the ETMEH, and one discrete output port (yellow)-DO_LoadSwitchControl are the pulses of control of the PMSG loading by the thermoelectric heaters. The main data (average and turbulent wind speed, initial torque for fast VAWT start) enter the green ports from the PLC program. The system provides recording in the PLC memory of the basic variables $\left(V_{\mathrm{w}}, \omega, \lambda, C_{\mathrm{P}}, T_{\mathrm{IM}}\right)$ by the orange ports.

\section{RESULTS AND DISCUSSION}

The adequacy of the WTE work was verified by comparing the results obtained experimentally on the HIL simulative setup with the analogical results of computer simulation in the MATLAB/Simulink of the operation of the studied VAWT with the direct-driving electrical and thermal generators.

\subsection{Power generation}

For power generation research, the simplest configuration of the stand was taken in the form of a non-regulated PMSG loading through a diode bridge to the B with a voltage of $13.2 \mathrm{~V}$. In this case, the corresponding windings of the two generator armatures were placed in phase and connected in series.

Steady state modes of WECS's work at the constant wind speeds from 3 to $8 \mathrm{~m} / \mathrm{s}$ were initially investigated. Comparison of the results obtained from the computer simulation of the experimental WECS in MATLAB/Simulink and the results of a similar study conducted in experiment as the waveforms of the basic variables recorded by the PLC shows that the maximum deviation of the experimental results from the theoretical ones does not exceed $10 \%$.

To test the adequacy of WTE operation in dynamic modes, a WECS's work was performed in the mode of electricity generating at turbulent wind speed. The test wind speed was modeled by the expression

$$
V_{\mathrm{w}}=V_{\mathrm{w} . \text { aver }}+2.2 \sin \left(\omega_{\mathrm{w}} t-0.8\right)-0.7 \cos \left(8 \omega_{\mathrm{w}} t+1.1\right)
$$

With an average wind speed of $V_{\mathrm{w} . a v e r} 5.0 \mathrm{~m} / \mathrm{s}$ and a lower circular frequency of wind speed change of $\omega_{\mathrm{w}}=0.24 \cdot 2 \pi / 60 \mathrm{~s}^{-1}$.

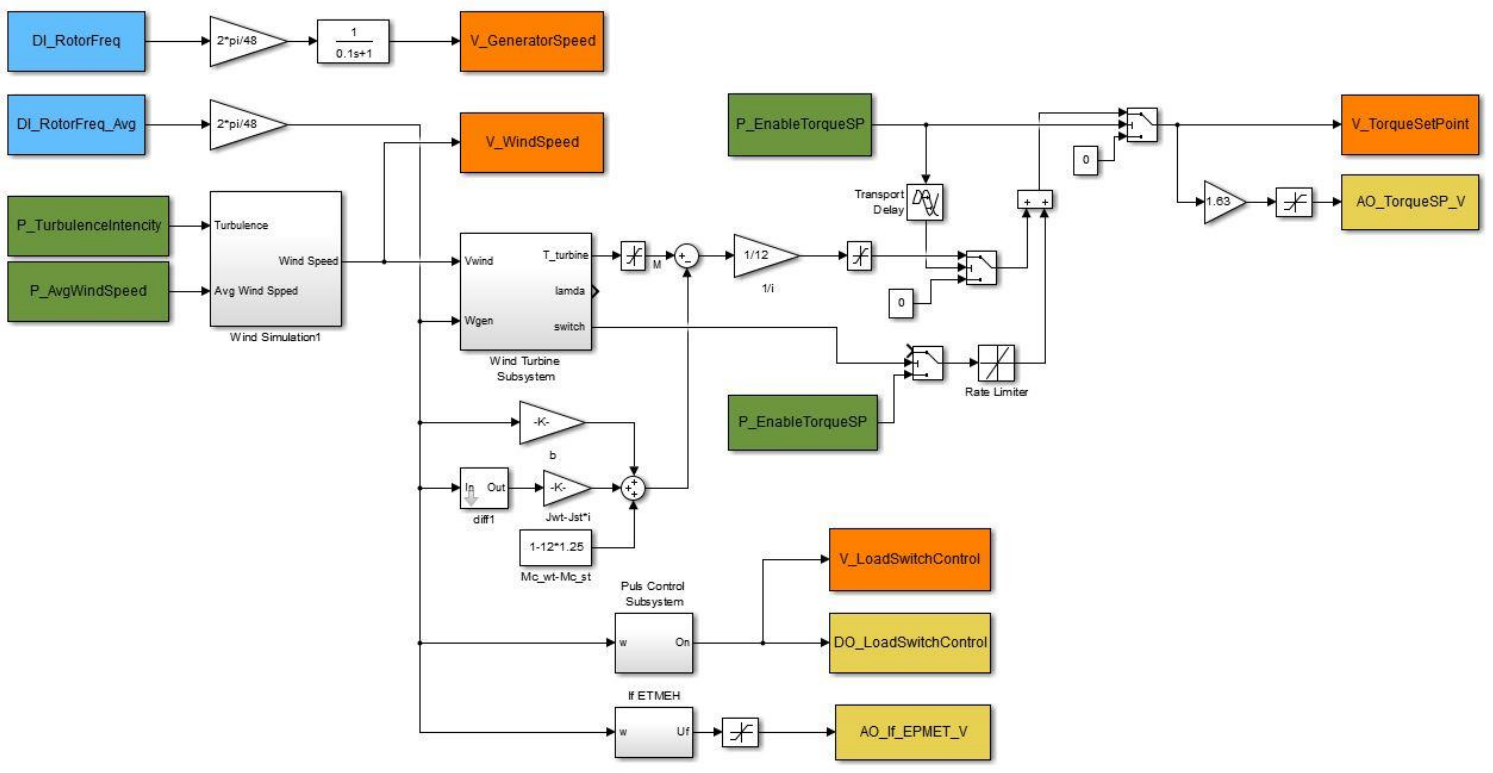

Figure 7. General control system for experimental research implemented in MATLAB/Simulink software and related to WP130 MK II controller 
Figure 8 shows the results of simulation and experiment at the wind test profile (8). Comparison of these results shows their high consistency (maximum error does not exceed 15\%).

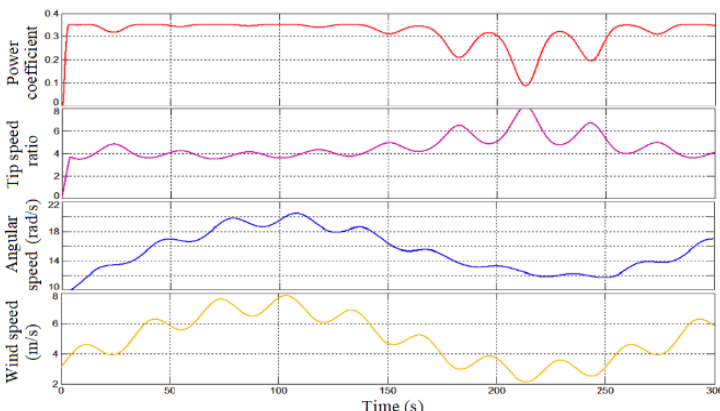

(a)

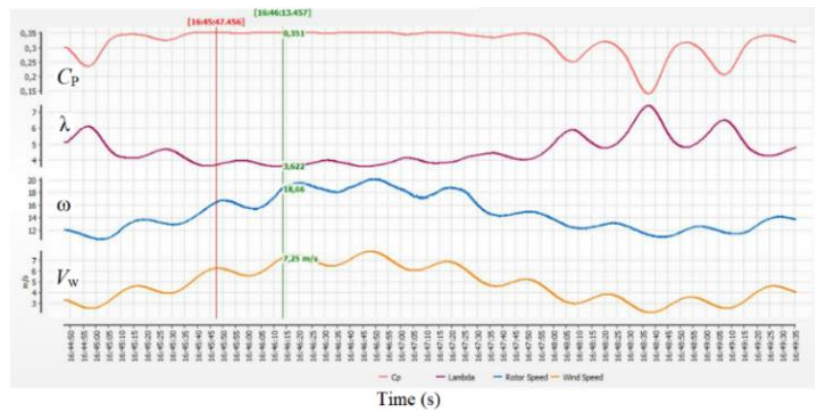

(b)

Figure 8. Basic variables obtained by the simulation (a) and for the experimental WECS's work with HIL simulative setup (b) for electricity generating and direct charging of the battery at the test turbulent wind speed (8)

\subsection{Heat generation}

Experimental studies of the ETMEH operation with the HIL simulative setup were performed in a closed-loop system with optimal control of the excitation to obtain maximum heat at variable wind speeds. The structure of such a control system is shown in Figure 9.

As a result of the previous experimental studies [18], the dependencies of the output thermal power of ETMEH (heat flux) $P_{\mathrm{h}}$ and the corresponding mechanical torque $T_{\mathrm{HG}}$ on the shaft of the thermal generator from the angular velocity $\omega$ and the excitation current $I_{\mathrm{f}}$ were obtained. These dependences in the simulation model are presented in the Look-up-table in Figure 9 the dotted section simulates the ETMEH's work.

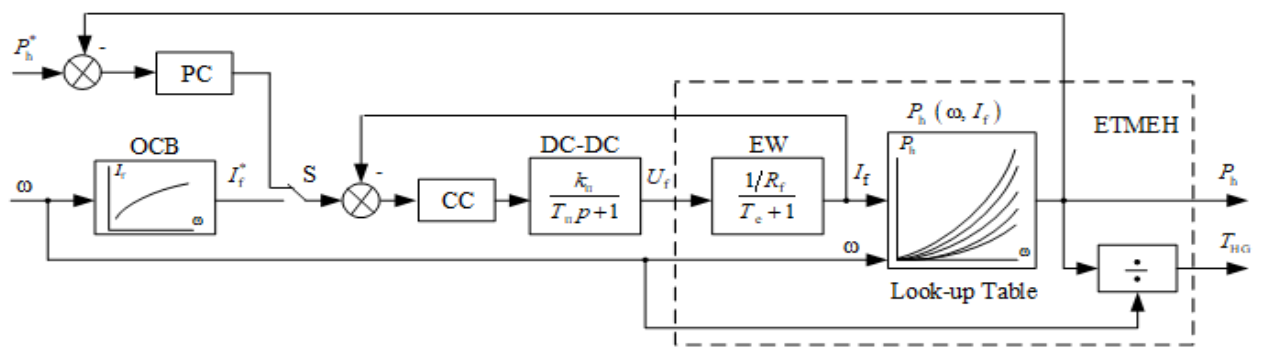

Figure 9. Block diagram of the ETMEH control system

The ETMEH control system has two structures that can be used in different CHP WECS's modes (switched by the key S): 1) feedback control subsystem with a power controller PC for stabilizing the heat flux according to the its reference $P_{\mathrm{h}}^{*} ; 2$ ) feedforward control subsystem which forms an optimal reference of the exitation current $I_{\mathrm{f}}^{*}$ with regard to the VAWT angular velocity. The optimum dependence $I_{\mathrm{f}}^{*}(\omega)$ which is written in the control block OCB is obtained by imposing the curve of the optimal VAWT power $P_{\mathrm{WT} . \text { opt }}=0.5 \rho_{\mathrm{a}} \operatorname{Ar} C_{\mathrm{P} . \max } V_{\mathrm{w}}{ }^{3}$ on the characteristics $P_{\mathrm{h}}\left(\omega, I_{\mathrm{f}}\right)$. As a result, the following dependence was obtained

$$
I_{\mathrm{f}}^{*}(\omega)=1.4421-0.07782 \omega+0.005191 \omega^{2}
$$

The automatic control of the ETMEH excitation current is provided in a closed-loop control system with an excitation current controller CC. Due to the small value of the electromagnetic time constant of the 
excitation winding $T_{\mathrm{e}}=L_{\mathrm{f}} / R_{\mathrm{f}}=0.328 \mathrm{H} / 3.97 \Omega=0.0826 \mathrm{~s}$, the $\mathrm{CC}$ has a proporsional structure with the gain of 50.

In the PLC as shown in Figure 7, the ETMEH excitation control subsystem is implemented in the block If EPMET based on the structure shown in Figure 9. The excitation current reference signal is transmitted through the ADC port AO_If_EPMET_V.

Figure 10(a) shows the obtained results of computer simulation of the experimental WECS's operation in the mode of thermal energy generation using the ETMEH with the given wind speed test profile (8). As can be seen from the obtained time dependences, the optimal control of the excitation current of the ETMEH leads to such mechanical loading on the shaft that provides the optimum VAWT angular velocity (from $20 \mathrm{~s}$ to $180 \mathrm{~s}$ and from $210 \mathrm{~s}$ to $340 \mathrm{~s}$ ). That in turn ensures the $C_{\mathrm{P}}$ value close to its maximum, and hence the maximum thermal power generation in the ETMEH rotor. In addition, a minimum value of VAWT angular velocity of $10 \mathrm{rad} / \mathrm{s}$ was set in the control system. Therefore, at low wind speeds, the excitation voltage reference begins to be adjusted by two-positions-turns on and turns off maintaining the stable minimum VAWT angular velocity (from $180 \mathrm{~s}$ to $210 \mathrm{~s}$ ).

Figure 10(b) shows in the same arrangement as Figure 10(a) the similar waveforms obtained in experimental studies of the CHP WECS's work with the HIL simulative setup in thermal energy generation mode. Comparison of the time dependencies of the same variables, obtained in the physical and mathematical experiments, shows their sufficient convergence-the error in the working range of wind speeds does not exceed $20 \%$.

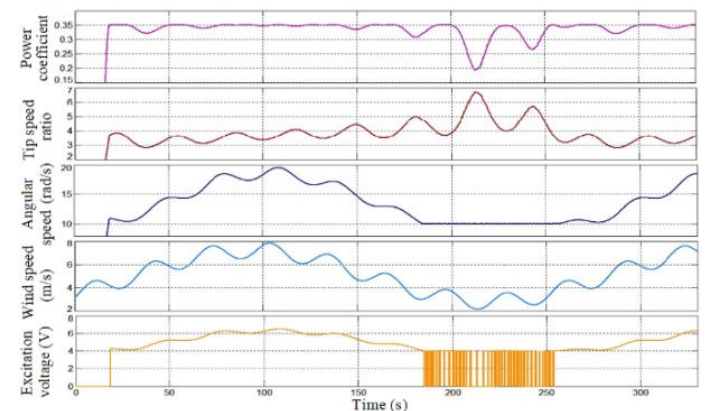

(a)

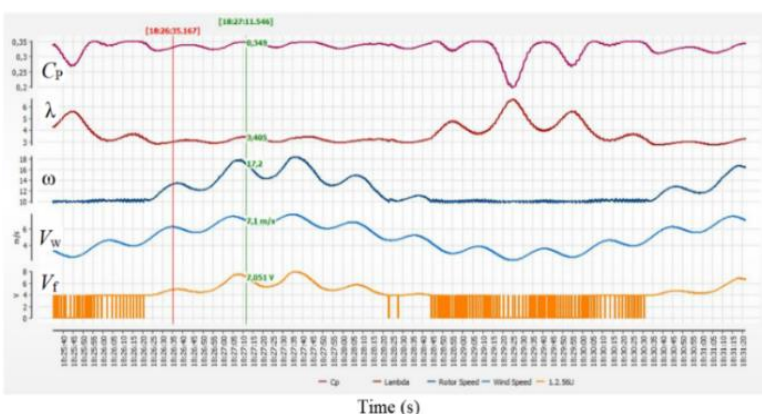

(b)

Figure 10. Basic variables obtained by simulation (a) and for the experimental WECS's work with HIL simulative setup (b) in the mode of heat generating by the ETMEH at the test wind speed (8)

\section{CONCLUSION}

The creation of CHP generating WECSs is a promising area for the development of low-capacity wind power that has not yet gained enough popularity. This paper proposes the HIL simulation setup for the study of CHP generating WECS, which consists of the WTE controlled by IM that drives two special generators-electrical PMSG and thermal ETMEH. Such a setup makes it possible to physically simulate the work of CHP generating WECS in different wind conditions, promptly and with the required reproducibility. This allows conducting a wide range of research for the development of control systems of optimal VAWT loading at each wind speed by each of the generators, as well as systems of energy flow control for both generators with a given priority or the required power generated [24]. Another promising area of research for the developed setup is the operation at wind speeds that exceed the nominal VAWT rating. In this case, different active stall control methods [25] are required in order to limit the power that the VAWT harvests from the wind. The use of CHP generating presents new opportunities to increase the efficiency of WECS at high wind speeds because of the possibility to consume two types of generated energy. However, there are new challenges to maintaining the mechanical strength of VAWT, as well as developing appropriate algorithms and control laws.

\section{REFERENCES}

[1] R. Lacal-Arántegui, "Globalization in the wind energy industry: contribution and economic impact of European companies", Renewable Energy, vol. 134, April 2019, pp. 612-628, 2019.

[2] Z. Simic, J. Havelka and M. Vrhovcak, "Small wind turbines-a unique segment of the wind power market", Renewable Energy, no. 50, February 2013, pp. 1027-1036, 2014. 
[3] B. J. Bukala, et al., "Small wind turbines: specification, design, and economic evaluation, Wind Turbines. Design, Control and Applications, Intech Open, pp. 73-93, 2016, DOI: 10.5772/62821.

[4] M. Bhutta, N. Hayat, A. Farooq, Z. Ali, S. Jamil and Z. Hussain, "Vertical axis wind turbine-a review of various configurations and design techniques", Renewable and Sustainable Energy Reviews, vol. 16, no. 4, pp. 1926-1939, 2012.

[5] A. Jain, S. Shankar and V. Vanitha, "Power generation using permanent magnet synchronous generator (PMSG) based variable speed wind energy conversion system (WECS): An overview", Journal of Green Engineering, vol. 7, no. 4, pp. 477-504, 2018.

[6] F. Diaz-Gonzalez, A. Sumper, O. Gomis-Bellmun and R. Villafafila-Robles, "A review of energy storage technologies for wind power applications", Renewable and Sustainable Energy Reviews, vol. 16, no. 4, pp. $2154-$ 2171, 2012.

[7] F. Asghar, S.-Y. Kim, and S. H. Kim, "Development of heat generating system based on small wind turbine system", in 2014 Joint 7th International Conference on Soft Computing and Intelligent Systems (SCIS) and 15th International Symposium on Advanced Intelligent Systems (ISIS), pp. 1209-1212, 3-6 Dec. 2014.

[8] O. Makarchuk, A. Rusek, I. Shchur and V. Shchur, "The electromagnetic transformer of mechanical energy into heat for wind turbine", Przeglad Elektrotechniczny (Electrical Review), vol. 91, no. 1, pp. 179-182, 2015.

[9] T. Okazaki, Y. Shirai and T. Nakamura, "Concept study of wind power utilizing direct thermal energy conversion and thermal energy storage", Renewable Energy, vol. 83, November 2015, pp. 332-338, 2015.

[10] B. Neammanee, S. Sirisumrannukul and S. Chatratana, "Development of a wind turbine simulator for wind generator testing", International Energy Journal, vol. 8, no. 1, pp. 21-28, 2007.

[11] F. Martinez, L. C. Herrero and S. de Pablo, "Open loop wind turbine emulator", Renewable Energy, vol. 63, , March 2014, pp. 212-221, 2014.

[12] M. A. Bhayo1, M. J. A. Aziz, N. R. N. Idris and A. H. M. Yatim, "Design and development of a wind turbine emulator for analyzing the performance of stand-alone wind energy conversion system", International Journal of Power Electronics and Drive System (IJPEDS), vol. 8, no. 1, pp. 454-461, March 2017.

[13] H. Garg and R. Dahiya, "Modeling and development of wind turbine emulator for the condition monitoring of wind turbine", International Journal of Renewable Energy Research, vol.5, no.2, pp. 591-597, 2015.

[14] T. O. Ajewole, K. O. Alawode, M. O. Omoigui and W. A. Oyekanmi, "Design validation of a laboratory-scale wind turbine emulator", Cogent Engineering, vol. 4, no. 1, $1280888,2017$.

[15] S. Szkolny and J. Małyszko, "Hardware-in-the-loop simulator for testing wind turbine generators", Technical Transactions on Electrical Engineering, vol.1-E, no. 8, pp. 229-239, 2015.

[16] H. Himani and N. Sharma, "Hardware-in-the-loop simulator of wind turbine emulator using labview", International Journal of Power Electronics and Drive System (IJPEDS), vol. 10, no. 2, pp. 971-986, June 2019.

[17] A. Riccobono, A. Helmedag, A. Berthold, N. R. Averous, R. W. De Doncker and A. Monti, "Stability and accuracy considerations of power hardware-in-the-loop test benches for wind turbines", IFAC PapersOnLine, vol. 50, no. 1, pp. 10977-10984, 2017

[18] Y. Vidal, L. Acho, N. Luo and C. Tutiven, "Hardware in the loop wind turbine simulator for control system testing", Wind Turbine Control and Monitoring, Chapter: 15, Springer, pp. 449-466, 2014.

[19] M. Neshati, P. Feja, A. Zuga, H. Roettgers, A. Mendonca and J. Wenske, "Hardware-in-the-loop testing of wind turbine nacelles for electrical certification on a dynamometer test rig", Journal of Physics: Conference Series, vol. $1618,032042,2020$.

[20] O. Makarchuk, A. Rusek, I. Shchur and V. Klymko, "Optimization of the design of electromagnetic transformer of mechanical energy into heat for VAWT”, Przeglad Elektrotechniczny (Electrical Review), vol. 91, no. 12, pp. 151$155,2015$.

[21] I. Shchur, Y. Biletskyi and V. Shchur, "Energy efficient and simple control of stand-alone combine heat-power generation small wind turbine", in 2017 IEEE First Ukraine Conf. on Electrical and Computer Engineering (UKRCON), Kyiv, Ukraine, pp. 483-488, 29 May-2 June 2017.

[22] L. Sheridan, "Rotation moment of inertia and applications Atwood machine with massive pulley energy of rotation", De Anza College, 12 March 2019.

[23] Technical Manual WP130 MK II Controller. Version 3.0, Mita-Teknik, 60 p., 2014.

[24] R. Yu, Y. Li and J. Cai, "Maximum power point tracking from a wind turbine emulator using a DC-DC converter controlled", International Journal of Control and Automation, vol. 7, no. 1, pp. 117-128, 2014.

[25] I. Shchur, A. Lozinskyi, Y. Biletskyi, B. Kopchak, V. Klymko and V. Shchur, "Passive stall control systems of power limitation modes for vertical axis wind turbines (VAWT)", Analysis and Simulation of Electrical and Computer Systems. Lecture Notes in Electrical Engineering, Heidelberg: Springer, Vol. 452, pp. 131-159, 2017. 


\section{BIOGRAPHIES OF AUTHORS}

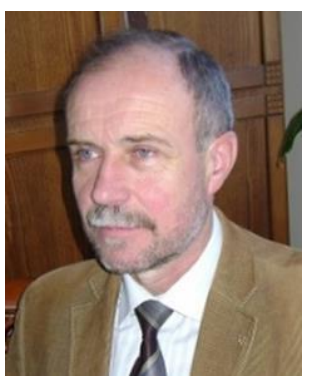

Ihor Shchur, Doctor of Science, Professor, the head of the Department of Electromechatronics and Computerized Electromechanical Systems, Institute of Power Engineering and Control Systems, Lviv Polytechnic National University, Ukraine. He has authored or coauthored more than 200 scientific publications, 6 books, and he holds 10 patents. He has managed 4 government scientific research projects and several projects for industry. His research interests include direct drives based on synchronous machines with permanent magnets, electric drives and control systems for electric vehicles, small power renewable energy conversion systems, including photovoltaic and wind turbine, hybrid energy storage systems including batteries and supercapacitors, energy-based mathematical modeling of multi-physics systems, and passivity-based controlled systems.

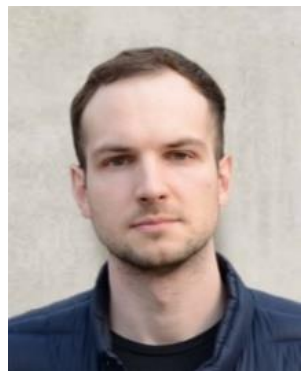

Vsevolod Shchur received his B.Sc. degree in Electrical Engineering from Lviv Polytechnic National University, Ukraine, in 2011. He continued his studies and received M.Sc. degree and Ph.D. degree from the same university in 2012 and 2017, respectively. Since 2012 he has been working as a software engineer at Mita-Teknik Company, which is one of the market leaders in the production of control systems for industrial wind turbines. His research interests are control systems for renewable energy generation units and electric vehicle technology.

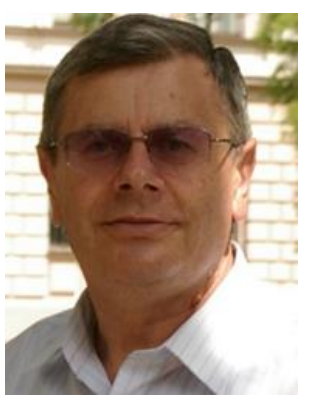

Ihor Bilyakovskyy received his diploma of engineer (Hons) from Lviv Polytechnic Institute, Ukraine, in 1980. He obtained his degree of candidate of sciences from the Lviv Polytechnic National University, Ukraine, in 1996. Since 1991, he has been a lecturer at Lviv Polytechnic National University and is now an Associate Professor at the Department of Electromechatronics and Computerized Electromechanical Systems. His current research interests are electric vehicle technology, renewable energy, modeling and design of electromechatronic converters.

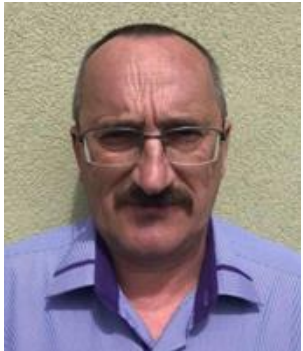

Mykhailo Khai has over 25 years of teaching and research experience at the Department of Electromechatronics and Computerized Electromechanical Systems, Institute of Power Engineering and Control Systems, Lviv Polytechnic National University, Ukraine. As Associate Professor, he specializes in modeling and researching of brushless synchronous generators and electrical devices. 